This item was submitted to Loughborough's Research Repository by the author.

Items in Figshare are protected by copyright, with all rights reserved, unless otherwise indicated.

\title{
The implications of organizational culture and trust in the working of virtual
} teams

PLEASE CITE THE PUBLISHED VERSION

PUBLISHER

(C) IMechE / Professional Engineering Publishing

VERSION

VoR (Version of Record)

LICENCE

CC BY-NC-ND 4.0

\section{REPOSITORY RECORD}

Dani, Samir, Neil D. Burns, C.J. Backhouse, and A.K. Kochhar. 2019. "The Implications of Organizational Culture and Trust in the Working of Virtual Teams". figshare. https://hdl.handle.net/2134/4583. 
This item was submitted to Loughborough's Institutional Repository (https://dspace.lboro.ac.uk/) by the author and is made available under the following Creative Commons Licence conditions.

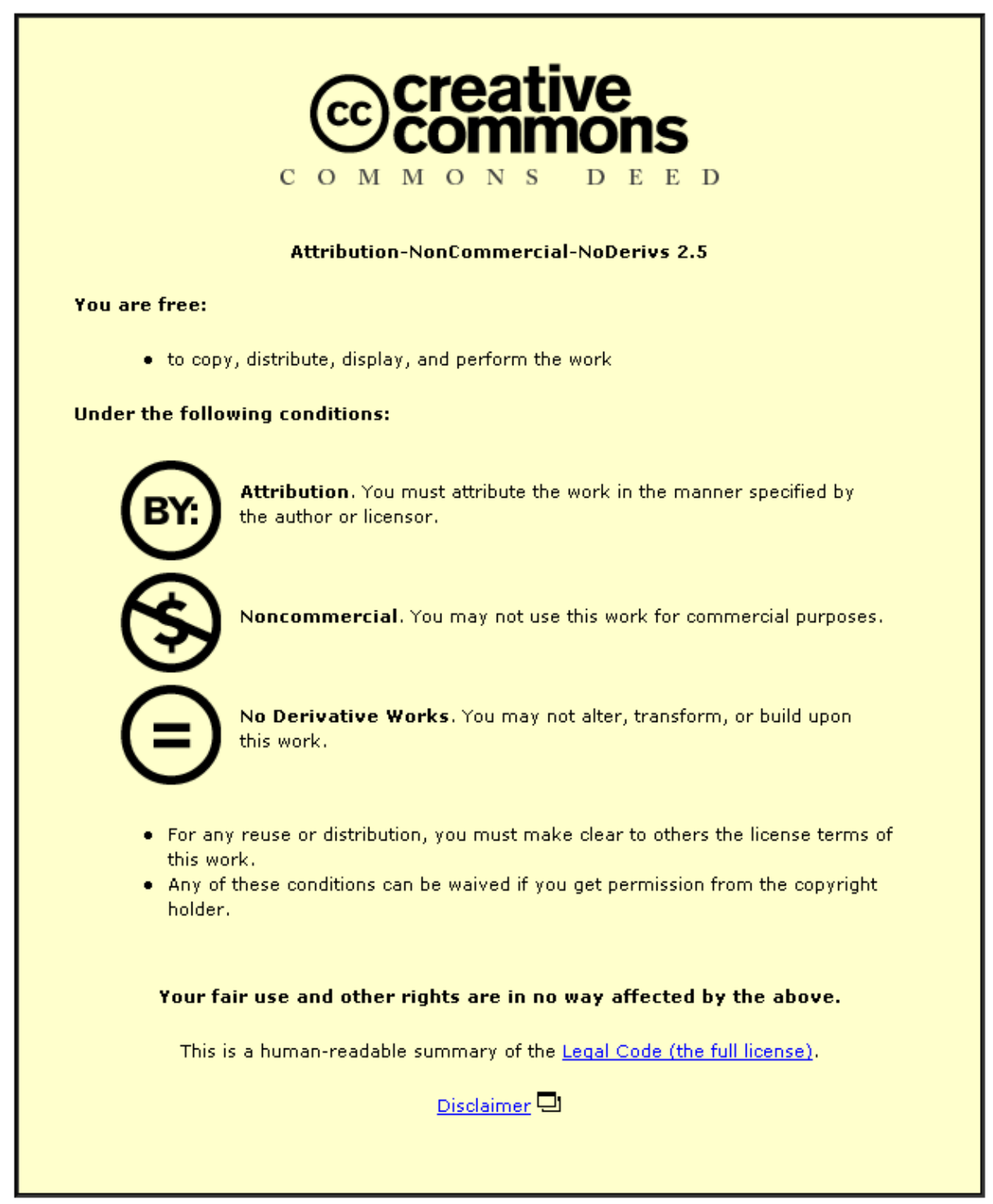

For the full text of this licence, please go to: http://creativecommons.org/licenses/by-nc-nd/2.5/ 


\title{
The implications of organizational culture and trust in the working of virtual teams
}

\author{
S S Dani ${ }^{1^{*}}$, N D Burns ${ }^{1}$, C J Backhouse ${ }^{1}$, and A K Kochhar ${ }^{2}$ \\ ${ }^{1}$ Wolfson School of Mechanical and Manufacturing Engineering, Loughborough University, Loughborough, UK \\ ${ }^{2}$ School of Engineering and Applied Sciences, Aston University, Birmingham, UK
}

The manuscript was received on 21 June 2005 and was accepted after revision for publication on 14 February 2006.

DOI: 10.1243/09544054JEM415

\begin{abstract}
The research described in this paper is concerned with examining trust issues in global teams and whether there are any implications for trust in respect to the cultural orientation of firms. Trust is the individual's (or group's) belief that another individual (or group) makes good faith efforts to behave in accordance with any commitments both explicit and implicit. This research was carried out as part of a collaborative project between Loughborough and Aston Universities. In this research it was decided to measure whether there was a relationship between perceived levels of trust in the organization and organizational culture as depicted by Cameron and Quinn in the working dynamics of virtual organizations. The research investigated the issue of trust in a number of business situations and showed that there does appear to be a relationship between trust and cultural orientation of firms for the working of virtual teams.
\end{abstract}

Keywords: organizational culture, trust, virtual teams, working dynamics

\section{RESEARCH CONTEXT}

The working practices in industry are changing, with organizations becoming more knowledge based, focusing upon their core competence, and willing to share their unique skills in alliances with partner organizations. These alliances are often in the form of virtual networks and make much use of globally based team-working. The virtual enterprise involves organizations and team members cooperating with globally dispersed partners in projects that often have a temporary nature lasting only for the duration of the contract. The virtual enterprise is a temporary relationship with two or more participants, which is formed, operated, and dissolved to accomplish specific short-term goals [1]. In this way of working, the individuals in the teams may know each other, particularly if they are working within the same organization, but often they do not. These teams depend upon trusting relationships developing quickly to obtain full benefit to be

*Corresponding author: Wolfson School of Mechanical and Manufacturing, Loughborough University, Loughborough, Leicestershire LE11 3TU, UK. email: S.Dani@lboro.ac.uk achieved from this style of working. Virtual teams represent a new form of organization that offers unprecedented levels of flexibility and responsiveness and has the potential to revolutionize the workplace. Virtual teams, however, cannot be implemented on faith and they do not represent an organizational panacea. Extensive research is needed to understand the design characteristics of successful virtual teams [2]. Drucker [3] has identified changes in organizations taking place now and speculated changes occurring over the next few years.

In a market place that is complex and uncertain, and becoming more complex, traditional organization structures and management concepts of the past are no longer viable.

1. Organizations comprising more knowledge workers are placing more and more emphasis upon trust between collaborating individuals, groups and companies.

2. The ability to respond to such change requires high levels of agility, which affects our traditional ideas of organization and management.

3. Technologies in manufacture and distribution are now utilizing greatly improved communication 
technology and converging to support the increased need for agility.

In this globally dispersed manner of working, where contracts, rules, and procedures may be difficult to apply, interpersonal trust becomes very important. 'If we are to enjoy the...benefits of the virtual organization, we will have to rediscover how to run organizations based more on trust than on control. Virtuality requires trust to make it work: technology on its own is not enough' [4]. Jones and Bowie [5] argue that 'the efficiency of virtual corporations depends on features - speed and flexibility - that require high levels of mutual trust and cooperation'. There are many definitions of trust. Trust is the individual's (or group's) belief that another individual (or group) makes good faith efforts to behave in accordance with any commitments both explicit and implicit. Baier's [6] definition of trust is the accepted vulnerability to another's possible but not expected ill-will (or lack of goodwill) towards someone. Other definitions of trust are given in references [7], [8], and [9].

Trust is generally influenced by:

(a) familiarity of the individuals in the relationship over a significant period of time;

(b) shared experiences and goals;

(c) reciprocal disclosure between individuals over time;

(d) demonstration of non-exploitation expressed over time.

According to Fox [10], trust is also related to the degree of regulation in the business. Ackroyd and Thompson [11] have further developed this concept. They developed Fox's arguments and suggest that there can be organizations that have either high or low trust regimes. Low trust regimes are characterized by general mistrust and suspicion of employees and are often related to the need for continuous surveillance over many aspects of behaviour. Such systems are also often associated with high degrees of regulation and surveillance of the individuals. Both Fox and Ackroyd and Thompson identify four types of relationship, as shown below.

1. Low trust: high regulation. This leads to recalcitrance/militancy.

2. Low trust: low regulation. This leads to an indulgency pattern.

3. High trust: high regulation. This leads to controlled autonomy.

4. High trust: low regulation. This leads to responsible autonomy.

The most desirable business culture to work in would appear to be high trust and low regulation. However, the high trust and high regulation is also a common form of work situation typical of modern lean companies and/or companies where there is a need for high levels of measurement for product or service traceability reasons. The low trust and high regulation environment is often produced by a vicious spiral of employee alienation combined with increasing surveillance to try to control the performance of the individuals, which in turn leads to a greater level of alienation and lower performance. In this situation management and labour are in a confrontation mode of behaviour.

Modern engineering design and to some extent project management and manufacture is often carried out by globally dispersed teams where highly professional engineers collaborate across global boundaries to produce sophisticated designs. In these temporary groups there is not really sufficient time for conventional views of trust to operate. Trust development in virtual teams also presents significant challenges because it is difficult to assess teammates' trustworthiness without ever having met them [12]. Moreover, as the life of many virtual teams is relatively limited, trust must quickly develop [13]. Yet, trust development is deemed crucial for the successful completion of virtual team projects [14]. Trust in temporary systems seems to lead to a unique view of trust that is rapidly able to manage the issues of vulnerability uncertainty, risk, and expectations. Meyerson et al. [15] developed the concept of 'swift-trust' for temporary teams formed around a task that has a finite lifetime. Often globally dispersed teams are composed of members with diverse skills, a limited history of working together, and sometimes with a limited prospect of working together in the future. According to Ratcheva and Vyakarnam [16] interpersonal relationships in virtual teams are likely to be built on similar personal relationships and professional characteristics and qualifications, and this may lead to the formation of swift-trust. If the team is highly culturally diverse and there are different objectives for group members, then it is likely that the formation of trust will take longer. Jarvenpaa and Leidner's [13] study suggests that swift-trust forms in global virtual teams with unique communication and behaviours. First, communication via the earliest keystrokes begins to establish trust. Task communication maintains trust while social communications (and explicit statements of commitment, excitement, and optimism) strengthen trust. Finally, the members' initial actions as well as their responses to one another are critical to trust development.

Swift-trust seems to occur when the situation is weak (see Mischel [17]), when there is some ambiguity in the situational context, and when the uncertainty is high. In addition, it is suspected that if an organization is increasingly operating as a virtual 
partner to others and is participating in increasing levels of virtual team working then the company cultural values would also change. This will be achieved by changing to a more high trust and low regulation cultural orientation. A number of virtual team studies have examined the role of cultural differences among team members. Cultural differences appear to lead to coordination difficulties [18-20], and create obstacles to effective communication $[19,21,22]$. Cultural and language differences are common in global virtual teams. However, subtler differences among team members from different regions of the same country may be enough to nega- tively impact a virtual team [23]. Cameron and Quinn [24] have defined four cultures and provided a means of measuring them in organizations. The four cultures are outlined in Fig. 1.

A typical bureaucratic and defensive hierarchical company may well have a low trust and high regulation managerial regime. This may have developed over time depending upon the attributions of managers in response to perceived worker soldiering or general misbehaviour. Another alternative is a high trust and high regulation company, probably more typical of the lean company with a clan culture that utilizes a modern version of Tayloristic principles.

\section{The Clan Culture}

An organization that focuses on internal maintenance with flexibility, concern for people, and sensitivity to customers.

A very friendly place to work where people share a lot of themselves. It is like an extended family. The leaders, or the heads of the organization, are considered to be mentors and perhaps even parent figures. The organization is held together by loyalty or tradition. Commitment is high. The organization emphasizes the long-term benefit of human resources development and attaches great importance to cohesion and morale. Success is defined in terms of sensitivity to customers and concern for people. The organization places a premium on teamwork, participation, and consensus.

\section{The Hierarchy Culture}

An organization that focuses on internal maintenance with a need for stability and control.

A very formalized and structured place to work. Procedures govern what people do. The leaders pride themselves on being good co-ordinators and organizers who are efficiency-minded. Maintaining a smooth-running organization is most critical. Formal rules and policies hold the organization together. The long-term concern is on stability and performance with efficient, smooth operations. Success is defined in terms of dependable delivery, smooth scheduling, and low cost. The management of employees is concerned with security of employment and predictability.

\section{The Adhocracy Culture}

An organization that focuses on external positioning with a high degree of flexibility and individuality.

A dynamic, entrepreneurial, and creative place to work. People stick their necks out and take risks. The leaders are considered innovators and risk takers. The glue that holds the organization together is commitment to experimentation and innovation. The emphasis is on being on the leading edge. The organization's long-term emphasis is on growth and acquiring new resources. Success means gaining unique and new products or services. Being a product or service leader is important. The organization encourages individual initiative and freedom.

\section{The Market Culture}

An organization that focuses on external positioning with a need for stability and control.

A results-oriented organization whose major concern is with getting the job done. People are competitive and goal-oriented. The leaders are hard drivers, producers, and competitors. They are tough and demanding. The glue that holds the organization together is an emphasis on winning. Reputation and success are common concerns. The long-term focus is on competitive actions and achievement of measurable goals and targets. Success is defined in terms of market share and penetration. Competitive pricing and market leadership are important. The organizational style is hard-driving competitiveness.

Fig. 1 Types of organizational cultures [24] 
People in this environment may be working to standard operating procedures that prescribe their work pattern, providing them with relatively little autonomy although they still operate within a trusting company environment. Another form is the high trust and low regulation company, essentially a people driven, adhocracy culture and organization based upon professionalism. This in many respects would appear to be appropriate for networks of professionals interacting as members of globally dispersed teams. The people can exert high autonomy and are trusted to apply their knowledge to the benefit of the organization. However, it is likely that as the organization becomes bigger the control and market needs will constrain the organizational options. The trust levels will thus reduce and as an opposite driver the regulation will increase.

\section{RESEARCH METHODOLOGY}

In this research it was decided to measure whether there was a relationship between perceived levels of trust in the organization and organizational culture as depicted by Cameron and Quinn [24] in the working dynamics of virtual organizations. The perceived levels of trust in the case of virtual organizations would essentially be the formation of swift-trust. Hence the focus was to investigate the cultural orientations required for swift-trust to propagate. In addition, the aim was also to show that companies that are transforming their business operations to become virtual, working then either as an emergent property or by deliberate strategy, are also working to change their cultures.

To summarize, the primary aims of the research project described in the paper were to determine the following.

1. Is there any evidence for the formation of swifttrust in temporary teams?

2. Does the requirement for higher levels of trust in virtual teams result in a change in the culture of the organization?

Although both of these aims deal with issues of trust in virtual teams, the first aim focuses on swifttrust, which is more of a short-term requirement for virtual teams, whereas the second aim focuses more on the long-term aspects of organizational culture change to foster trust in virtual teams. Three companies agreed to be a sample for this research. Company 1, which is an engineering firm in the East Midlands, is a global firm with offices in the UK and USA. The company was in the process of setting up global design teams (GDTs) and was interested in studying the issues of trust formation and communication issues in the working of GDTs. Company 2 and Company 3 participated in this research with a view to studying the requirements needed for cultural change in order to introduce virtual teams as a part of their strategy.

\section{Case 1: GDT working in an engineering company}

Initially it was decided to investigate as much as possible the practical aspects of globally dispersed team-working. In addition, it was hoped by analysing an actual team-working situation in industry that some understanding might be provided to answer the issues associated with the speed of formation of trust (aim 1). To extend this, a study was carried out at a major international company producing engineered products in the East Midlands in the UK. In total 356 professionally trained engineers worked in several globally dispersed plants primarily in the UK and the USA. Global team-working was common in the company, primarily between engineers in the UK and the USA, and although mainly involving internal employees it did frequently involve suppliers and customers of the company. A questionnaire to study opinions that employees had about issues related to global working was sent to a random sample of 100 engineers who took part in global teamwork; 86 returns were obtained. The sample of personnel used included design engineers in early to mid career and in their normal functions. Four principal forms of data were obtained: (a) factual data about the respondent and their function, location, etc.; (b) how often they worked within a GDT, and their preferred method of communication; (c) how their GDT compared to design team-working carried out with co-located members; and (d) their opinion of how GDT operation could be improved - particularly related to the trust issue. In addition, there was a focus group meeting consisting of design engineering team leaders, to explore the concerns and issues of global team-working that were highlighted through the questionnaire.

\section{Case 2: cultural assessment to determine whether companies employing global teams and virtual working are changing their cultures}

An in-depth culture survey was carried out to investigate whether organizations that express a wish to become more virtual or to increase virtual working are transforming to become more trusting, or at least as ones who value trust. Two companies were selected for the cultural assessment. In the survey response Company 2 indicated that it was already 
operating as a virtual company. It employed a significant number of knowledge workers (primarily consultants) and they were operating in a globally dispersed team environment and often other team participants were from organizations distributed around the globe. The engineers in the company were working as members of virtual teams in a consultancy mode of operation on relatively short-term projects (less than a year). Company 2 employed about 200 people and with the cooperation of the company's personnel department 95 per cent of the employees in the company took part in the survey. Company 3 was, from a cultural perspective, more traditional in nature. It is a major supplier of health care products and had been operating as a medium sized (about 500 employees) formal and hierarchical company for many years. However, recently the company was being asked to bid for work in electronic auctions and was also becoming more involved with virtual team-working, where it provided its core competence to projects and it perceived that it would have to work in this manner more in future years. Both firms wanted their cultures to be assessed and to see how people and the particular way of working more in dispersed project teams in the company were propelling the company to a change in culture.

From the investigation the aim was then to develop some general guidelines providing advice to companies about culture, trust, etc., that would result in effective virtual working. It soon became apparent that the in-depth industrial work on incompany trust is particularly sensitive and the companies requested that their names would not be revealed. In both companies about 70 per cent of the employees responded by filling in the Cameron and Quinn questionnaire (Organizational Culture Assessment Instrument, or OCAI). The Cameron and Quinn [24] competing values framework was used to assess the culture. The OCAI questionnaire was used to gain an insight into the organizational culture based on the OCAI typology, viz. adhocracy, clan, hierarchical, and market. The OCAI produces an overall organizational culture profile. Six dimensions of organizational culture are assessed, based on a theoretical framework of how organizations work and the kinds of values upon which their cultures are founded. The OCAI identifies what the current organizational culture is like as well as what the organization's preferred, future culture should be like. The respondents were asked to complete the OCAI questionnaire (shown in the Appendix) to depict their perception of the culture in their organizations and then to complete the same questionnaire to depict their preferred culture for their organization.

\section{RESEARCH RESULTS}

\section{Case 1: GDT working in an engineering company}

A. Questionnaire. Some of the responses from the questionnaire are depicted below:

(a) Types of teams engineers work in?

Engine design (40), Electrical systems (10), Hydraulics (18), Other design (15)

(b) How long did you work in a team?

Less than 1 year (36), 1-2 years (22), 2-3 years (8), 3-4 years (6), more than 4 years (14)

(c) Indicate the percentage of your time that you spend working with team members who are not in the same geographic region as you.

0-20 per cent (46), 21-40 per cent (24), 41-60 per cent (14), above 61 per cent (2)

(d) Did an international time difference make it difficult to find a convenient time to hold a meeting?

52 per cent said 'yes' and 34 per cent said 'no'

(e) Globally dispersed teams deliver objectives as effectively as co-located teams.

Disagree (42), No view (12), Agree (32)

(f) What is the correct size for a project team?

The two largest responses were: 5-10 members (36), 10-15 members (28)

The focus was on the communication methods and how these contributed to the building of swift-trust. The synopsis of the main responses regarding communication are given in Table 1 . The methods of communication play an important part in building of trust as recorded by references [13] and [25].

For the question on communication methods: email was the main communication medium

Table 1 Communication experience

\begin{tabular}{llr}
\hline Communication experience & Yes & No \\
\hline $\begin{array}{l}\text { Was the appropriate communications } \\
\quad \text { technology available to conduct the meeting? }\end{array}$ & 76 & 10 \\
$\begin{array}{l}\text { Was there an open and trusting atmosphere } \\
\quad \text { during the meeting? }\end{array}$ & 72 & 14 \\
$\begin{array}{l}\text { Could you openly question the opinion of others? } \\
\text { Were there any social or personal conversations? }\end{array}$ & 64 & 22 \\
$\begin{array}{l}\text { Were agreements effectively reached and } \\
\quad \text { documented? }\end{array}$ & 68 & 18 \\
& & \\
\hline
\end{tabular}


(used daily); on average 12 face-to-face meetings per team took place per year; video conferencing, email conferencing, or audio conferencing took place at least once a week.

B. Focus groups. The questionnaire results provided a valuable insight for the research sample by depicting that the respondents, though being globally distributed, found that the meetings were held in trusting environments. Also, there were a large number of face-to-face meetings coupled with video conferencing happening in the conduct of these virtual teams. Did the type of communication have any effect on the meeting environment being very trusting? In order to study this issue and some of the managerial issues in depth, a focus group was initiated, which was comprised of team leaders. The sample size for this focus group discussion was 5 . One of the conclusions from the focus group was the dominance of the local management work programme and objectives over the global team programme and objectives. All the team leaders thought that pressures and demands placed upon them were more immediate and could not be ignored as easily as those imposed by the GDT or remote manager. Also face-to-face meetings were the only way to ensure that rapport was achieved. Although the teams were globally dispersed for most of their work the members did seem to travel considerably and on average there were up to 12 face-to-face meetings per year, although when long distances were involved this reduced to 1 or 2 per year. The face-to-face meetings were considered to be very important in building trust and much better than no-physicalcontact media such as a phone call or video conferencing.
Location and skill appeared to be the most important criteria for the selection of team members. Most of the people in the teams did have some knowledge of other team participants although they may not have worked in a virtual team with them before. The tasks were generally complex engineering design tasks. According to the views of the respondents, trust levels were high right from the start of the project and this appeared to be based upon shared professionalism, identification with the company, the shared need to succeed, and solidarity of beliefs between a set of similarly competent engineers. There was no evidence of opportunistic behaviour by one or more individuals at the expense of others. Opportunistic behaviour was considered to be unlikely. However, the view was expressed that if any opportunistic behaviour did take place then trust would be compromised for future working relationships with the individuals concerned, and since there was a significant chance that they would work together again some time in the future there were strong constraints against opportunism.

The results showed the extent of the global teamworking within the company and involving external partners. It did show clearly that face-to-face meetings helped in trust formation among the members.

\section{Case 2: cultural assessment to determine whether companies employing global teams and virtual working are changing their cultures}

The OCAI responses from both companies were calculated and then summed to find an averaged response for the existing and preferred culture profiles. This is depicted in Figs 2 and 3.

\begin{tabular}{|l|r|r|}
\hline & Existing & Preferred \\
\hline Clan $[\mathrm{A}]$ & 19 & 33 \\
\hline Adhocracy [B] & 15 & 21 \\
\hline Market [C] & 34 & 20 \\
\hline Hierarchy [D] & 32 & 27 \\
\hline
\end{tabular}

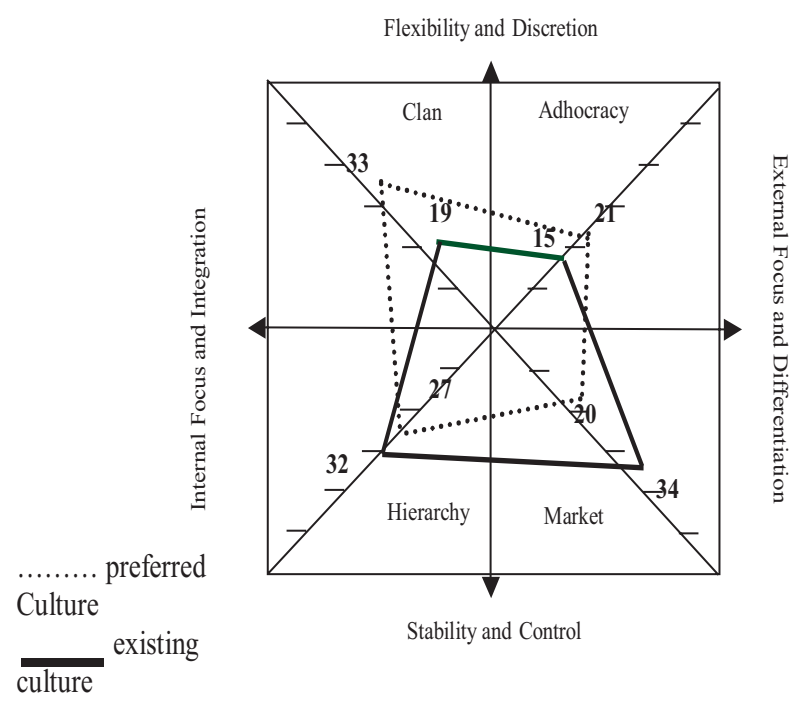

Company 2- The OCAI profile

Fig. 2 The cultural orientations of Company 2 


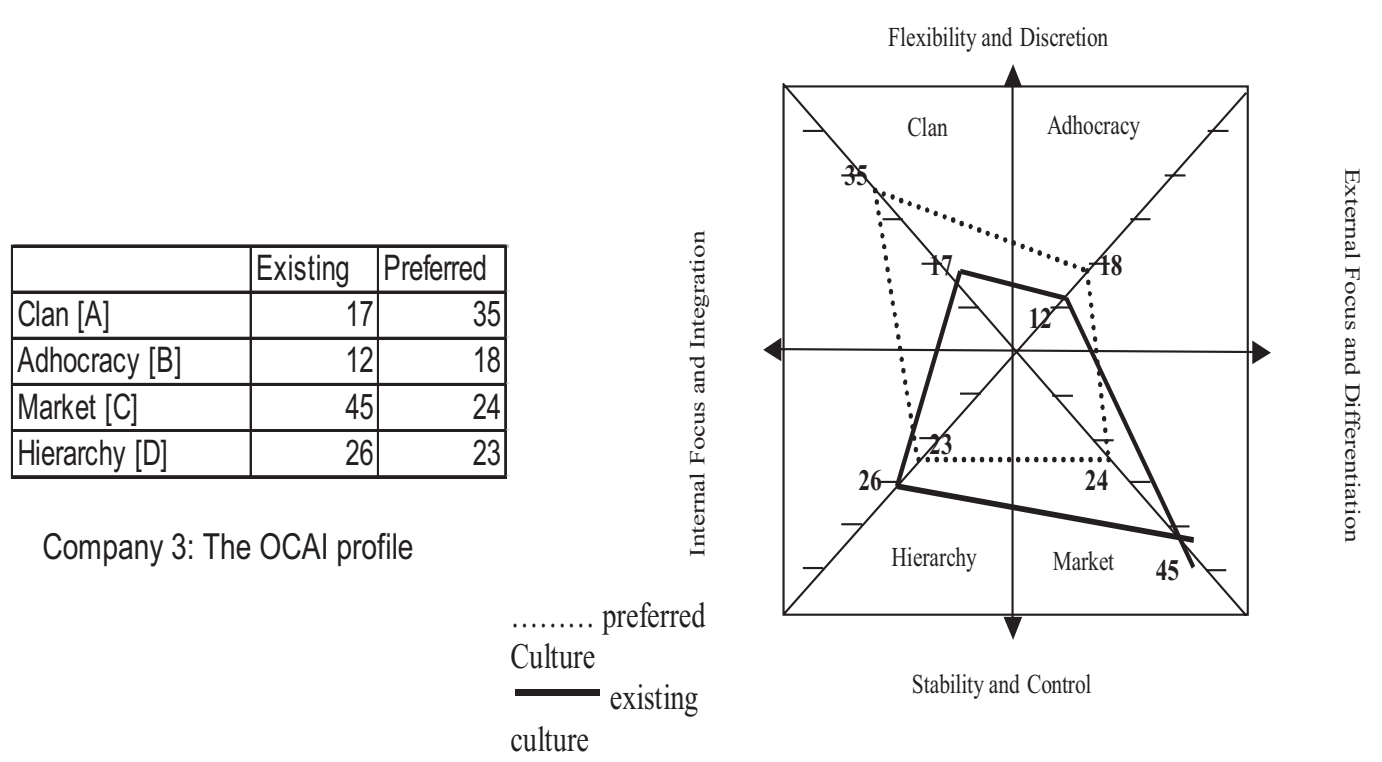

Fig. 3 The cultural orientations of Company 3

The existing and preferred culture results of Company 2 and Company 3 are shown on the competing values framework. Each line on the diagonals represents 10 points. Both companies registered an increased interest in transforming to a clan culture. One interpretation of this is that the clan culture is often associated with high trust and high regulation - it is efficient but at the same time is strongly associated with a team spirit. In many respects this may be an appropriate culture for virtual working but there are many drivers influencing business culture; e.g. increasing global competition is probably a more significant driver towards the clan culture. When the measurements were carried out, the present state cultural measurement in Company 2 had an emphasis upon hierarchy (OCAI score 32) and market (OCAI score 34), this being a common mix for a competitive defender or analyser company. The perception of the employees and to a large extent their aim was to change to a clan culture (OCAI score 33) (see Fig. 2). They hoped that this would enable them to achieve high efficiency but still retain trust.

Company 3 described themselves as virtual, forming temporary alliances with a variety of other companies, using computer-based communication, etc. However, this did not appear to be a new way of working for them. Their pattern was typical of an engineering consultancy company. The company expressed a strong wish to develop its globally based virtual partnership strategy and it was not sure that its present culture was appropriate, particularly to develop more autonomous and high trust working patterns. For Company 3 the existing state was primarily market oriented
(OCAI score 45) but the desired state again was to become more clan like (OCAI score 35).

\section{DISCUSSION AND CONCLUSIONS}

The primary aims of the research project described earlier in the paper were to determine the following.

1. Is there any evidence for the formation of swifttrust in temporary teams?

2. Does the requirement for higher levels of trust in virtual teams result in a change in the culture of the organization?

Research was conducted in parallel stages in the respondent companies and the data were analysed to provide an insight into the aims identified for this research.

\section{Aim 1: Is there any evidence for the formation of swift-trust in temporary teams?}

From the analysis of data collected from Company 1 there does seem to be evidence for the formation of swift-trust in these highly professional teams of design engineers. The questionnaire as well as the focus group discussion identified the fact that trust levels were high right from the start of the project. The effect of communication on the maintenance of trust during the working of these teams was also suggested. It was also evident that there was a storming phase of team development later in the project during the face-to-face meetings. It was suggested that 'face-to-face' meetings were the only way to ensure that rapport was achieved. It was considered more appropriate to hold a meeting in a single 
location with all parties when setting up a new team. Video conferencing was one of the cost-effective methods used to generate some visual method of communication if 'face-to-face' meetings were not appropriate. However, it was found that there were issues with using 'video conferencing', which related to the inability to read body language, lack of a physical presence, and a time delay between different locations for communicating. It was thus suggested to research into the aspects of making 'video conferencing' more appropriate. When the team members were distant from each other they worked on independent work packages and mutual adjustment of the work occurred when team members conducted their face-to-face meetings. In addition, swift-trust was observed based upon common goals of the group and a belief in each other's professional integrity. The research is continuing in order to obtain a larger industrial sample size and to test the relationship between trust and culture.

\section{Aim 2: Does the requirement for higher levels of trust in virtual teams result in a change in the culture of the organization?}

The two companies tested using the Cameron and Quinn competing values framework showed a consistent wish to become more like a clan company, which is generally associated with high trust and high regulation and is in line with lean thinking. It did show evidence that the respondents from both companies worked in low trust environments and showed a preference for working in a high trust environment, which was the preference for a clan culture. Therefore, although both companies were significantly different in nature, their cultural patterns were not greatly different. Both companies were trying to change from a mixture of hierarchy and market driven to more of a clan type culture. The clan type culture is significantly associated with participation and involvement but within a highly efficient framework. The drive to produce a particular culture may well result from many sources and the simple statement of becoming a virtual company with more global team-working is just one of those many pressures. For Companies 2 and 3 the drivers to change the culture were primarily competitive pressures to cut cost and to become more responsive. Virtual working was one of the perceived enablers. Although virtual working was an enabler towards culture change, the preferred culture as depicted by the respondents was clan in both companies, which seems to suggest that the respondents preferred moving towards a more trusting environment. The respondents thus seem to suggest that they would prefer a high trusting organization when working as virtual teams.
It is known that there are many forms of virtuality and the present research has confirmed this view. Typically the taxonomy in reference [26] has identified a variety of forms, some appropriate for large defensive companies and some appropriate for start-up prospective firms. This research confirms the understanding that there is no 'one solution fits all' form of virtuality. Rather it is the selection of an appropriate form to match a number of market, product, and strategy variables followed by an appropriate implementation to suit that form of company that is important. Some virtual partnerships will inevitably involve large organizations while some small firms will have the features of adhocracy with high trust and low regulation throughout. This research has depicted the importance that communication methods have in developing and maintaining trust in virtual teams. Also companies who intend to participate in virtual team-working may need to change their culture to one that fosters more trust. This will help internal teams to work consistently in a trusting manner and also help when employees participate in external teams. The findings from this research, though very valid for the data sample, need further work to ascertain the actual process of culture change when going virtual and the effect on the internal and external communication networks of the company.

\section{ACKNOWLEDGEMENT}

The authors would like gratefully to acknowledge the support that the Engineering and Physical Sciences Research Council, UK, has extended towards them for this work.

\section{REFERENCES}

1 Reid, R. L., Tapp, J. B., Liles, D. H., Rogers, K. J., and Johnson, M. E. An integrated management model for virtual enterprises: vision, strategy and structure. In Proceedings of the International Conference on Engineering and technology management (IEMC 96), Vancouver, British Columbia, 18-20 August 1996, pp. 522-527.

2 Powell, A., Piccoli, G., and Ives, B. Vitual teams: a review of current literature and directions for future research. The DATA BASE for Advances in Information Systems, 2004, 35(1), Winter, 6-36.

3 Drucker, P. F. Managing in the next society, 2002 (Butterworth-Heinemann, Oxford).

4 Handy, C. Trust and the virtual organization: how do you manage people whom you do not see? Harvard Business Rev., 1995, 73, 40-48.

5 Jones, T. W. and Bowie, N. E. Moral hazards on the road to the 'virtual' corporation. Business Ethics Q., 1998, 8, 273-292. 
6 Baier, A. Trust and antitrust. Ethics, 1986, 96, 231-260.

7 Bacharach, M. and Gambetta, D. Trust as type detection. In Trust and deception in virtual societies (Eds C. Castelfranchi and Y.-H. Tan), 2001, pp. 1-26 (Kluwer Academic, Dordrecht, The Netherlands).

8 Giffin, K. The contribution of studies of source credibility to a theory of interpersonal trust in the communication process. Psycholog. Bull., 1967, 68(2), 104-120.

9 Jones, A. J. I. On the concept of trust. Decision Support Systems, 2002, 33, 225-232.

10 Fox, A. Beyond contract: work power and trust relations, 1974 (Faber and Faber, London).

11 Ackroyd, S. and Thompson, P. Organizational misbehaviour, 1999 (Sage, London).

12 McDonough, E., Kahn, K., and Barczak, G. An investigation of the use of global, virtual, and collocated new product development teams. J. Product Innovation Managmt, 2001, 18(2), 110-120.

13 Jarvenpaa, S. L. and Leidner, D. E. Communication and trust in global virtual teams. Organization Sci., 1999, 10, 791-815; also published in Communication and trust in global virtual teams, J. Computer Mediated Commun., June 1998, 3(4); http://jcmc.indiana. edu/vol3/issue4/jarvenpaa.html.

14 Sarker, S., Lau, F., and Sahay, S. Using an adapted grounded theory approach for inductive theory building about virtual team development. The DATA BASE for Advances in Information Systems, 2001, 32(1), 38-56.

15 Meyerson, D., Weick, K. E., and Kramer, R. M. Swift trust and temporary groups. In Trust in organizations, 1996, ch. 9 (Sage, Thousand Oaks, California); also presented at the Conference on Trust in Organizations, Graduate School of Business, Stanford University, California, 14-15 May 1994.

16 Ratcheva, V. and Vyakarnam, S. Exploring team formation processes in virtual partnerships. Integrated Mfg Systems, 2001, 12(7), 512-523.

17 Mischel, W. The interaction of person and situation. In Personality at the crossroads: current issues in interactional psychology (Eds D. Magnusson and N. Endler), 1977, ch. 25 (Lawrence Erlbaum Associates).

18 Johansson, C., Dittrich, Y., and Juustila, A. Software engineering across boundaries: student project in distributed collaboration. IEEE Trans. Professional Commun., 1999, 42(4), 286-296.

19 Kayworth, T. and Leidner, D. The global virtual manager: a prescription for success. Eur. Managmt J., 2000, 18(2), 183-194.
20 Maznevski, M. and Chudoba, K. Bridging space over time: global virtual team dynamics and effectiveness. Organization Sci., 2001, 11(5), 473-492.

21 Sarker, S. and Sahay, S. Information systems development by US-Norwegian virtual teams: implications of time and space. In Proceedings of the Thirty-Fifth Annual Hawaii, International Conference on System sciences, Hawaii, 2002, pp. 1-10.

22 Van Ryssen, S. and Hayes Godar, S. Going international without going international: multinational virtual teams. J. Int. Managmt, 2000, 6, 49-60.

23 Robey, D., Khoo, H., and Powers, C. Situated learning in cross-functional virtual teams. IEEE Trans. Professional Commun., 2000, 43(1), 51-66.

24 Cameron, K. S. and Quinn, R. E. Diagnosing and changing organizational culture, based on the competing values framework, 1999 (Addison-Wesley, Reading, Massachusetts).

25 Tuckman, B. W. Stages of small group development. Group and Organisational Studies, 1977, 2(4), 419-427.

26 Bradt, R. (1998) Virtual organisations: a simple taxonomy; http://www.infothink.com/resources/ virtual_org_summary.html (accessed 12 December 2005).

\section{APPENDIX}

\section{The organizational culture assessment}

\section{Instructions}

The OCAI consists of six questions. Each question has four alternatives. Read each alternative carefully as differences may be subtle. Divide 100 points among these four alternatives depending on the extent to which each alternative is similar to your perception of the organization. Give a higher number of points to the alternative that is most similar to your organization. For example, in question 1 , if you think alternative A is very similar to your organization, alternatives $\mathrm{B}$ and $\mathrm{C}$ are somewhat similar, and alternative D is hardly similar at all, you might give 55 points to $A, 20$ points each to $B$ and $C$, and 5 points to D (see Fig. 4). Just be sure that your total equals 100 for each question. (Adapted from Kim S. Cameron and Robert E. Quinn [24]). 


\begin{tabular}{|c|c|c|c|}
\hline \multicolumn{2}{|c|}{ 1. Dominant Characteristics } & \multirow[t]{2}{*}{ Now } & \multirow[t]{2}{*}{ Preferred } \\
\hline $\mathrm{A}$ & $\begin{array}{l}\text { The organisation is a very personal place. It is } \\
\text { like an extended family. People seem to share } \\
\text { a lot of themselves. }\end{array}$ & & \\
\hline B & $\begin{array}{l}\text { The organisation is a very dynamic and } \\
\text { entrepreneurial place. People are willing to } \\
\text { stick their necks out and take risks. }\end{array}$ & & \\
\hline $\mathrm{C}$ & $\begin{array}{l}\text { The organisation is very results centred. } \\
\text { A major concern is with getting the job done. } \\
\text { People are very competitive and achievement } \\
\text { centred }\end{array}$ & & \\
\hline $\mathrm{D}$ & $\begin{array}{l}\text { The organisation is a very controlled and } \\
\text { structured place. Formal procedures } \\
\text { generally govern what people do. }\end{array}$ & & \\
\hline & ( & 100 & 100 \\
\hline \multicolumn{2}{|c|}{ 2. Organisational Leadership } & Now & Preferred \\
\hline $\mathrm{A}$ & $\begin{array}{l}\text { The leader ship in the organisation is generally } \\
\text { considered to demonstrate mentoring, facilitating } \\
\text { or nurturing. }\end{array}$ & & \\
\hline B & $\begin{array}{l}\text { The leader ship in the organisation is generally } \\
\text { considered to demonstrate entrepreneurship, } \\
\text { innovating, or risk taking. }\end{array}$ & & \\
\hline $\mathrm{C}$ & $\begin{array}{l}\text { The leader ship in the organisation is generally } \\
\text { considered to demonstrate a no-n onsense, } \\
\text { aggressive, results-orientated focus. }\end{array}$ & & \\
\hline $\mathrm{D}$ & $\begin{array}{l}\text { The leader ship in the organisation is generally } \\
\text { considered to demonstrate co-ordination, } \\
\text { organizing, or smooth running efficiency. }\end{array}$ & & \\
\hline & Total & 100 & 100 \\
\hline \multicolumn{2}{|c|}{ 3. Management of Employees } & Now & Preferred \\
\hline A & $\begin{array}{l}\text { The management style in the organisation is } \\
\text { characterised by teamwork, consensus and } \\
\text { participation. }\end{array}$ & & \\
\hline $\mathrm{B}$ & $\begin{array}{l}\text { The management style in the organisation is } \\
\text { characterised by individual risk-taking, } \\
\text { innovation, freedom and uniqueness. }\end{array}$ & & \\
\hline $\mathrm{C}$ & $\begin{array}{l}\text { The management style in the organisation is } \\
\text { characterised by hard-driving competitiveness, } \\
\text { high demands and achievement. }\end{array}$ & & \\
\hline $\mathrm{D}$ & $\begin{array}{l}\text { The management style in the organisation is } \\
\text { characterised by security of employment, conformity, } \\
\text { predictability, and stability in relationships. }\end{array}$ & & \\
\hline & Total & 100 & 100 \\
\hline
\end{tabular}

\begin{tabular}{|c|c|c|c|}
\hline \multicolumn{2}{|c|}{ 4. Organisation Glue } & \multirow[t]{2}{*}{ Now } & \multirow[t]{2}{*}{ Preferred } \\
\hline A & $\begin{array}{l}\text { The glue that holds the organisation together } \\
\text { is loyalty and mutual trust. Commitment to } \\
\text { th is organisation runs high. }\end{array}$ & & \\
\hline $\mathrm{B}$ & $\begin{array}{l}\text { The glue that holds the organisation together } \\
\text { is commitment to innovation and development. } \\
\text { There is an emphasis on being on the cutting edge. }\end{array}$ & & \\
\hline $\mathrm{C}$ & $\begin{array}{l}\text { The glue that holds the organisation together } \\
\text { is the emphasis on achievement and goal } \\
\text { accomplishment. Aggressiveness and winning } \\
\text { are common themes. }\end{array}$ & & \\
\hline $\mathrm{D}$ & $\begin{array}{l}\text { The glue that holds the organisation together } \\
\text { is formal rules and policies. Maintaining a } \\
\text { smooth-running organisation is important. }\end{array}$ & & \\
\hline & 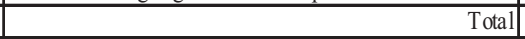 & 100 & 100 \\
\hline \multicolumn{2}{|c|}{ 5. Strategic Emphases } & Now & Preferred \\
\hline $\mathrm{A}$ & $\begin{array}{l}\text { The organisation emphasises human development. } \\
\text { High trust, openness and participation persist. }\end{array}$ & & \\
\hline B & $\begin{array}{l}\text { The organisation emphasises obtaining new } \\
\text { resources and creating new challenges. Trying } \\
\text { new things and looking for opportunities are } \\
\text { valued. }\end{array}$ & & \\
\hline $\mathrm{C}$ & $\begin{array}{l}\text { The organisation emphasises competitive actions } \\
\text { and achievement. Hitting stretch targets and } \\
\text { winning in the market place are dominant. } \\
\end{array}$ & & \\
\hline $\mathrm{D}$ & $\begin{array}{l}\text { The organisation emphasises continuity and } \\
\text { stability. Efficiency, control and smooth } \\
\text { operations are important. }\end{array}$ & & \\
\hline & Total & 100 & 100 \\
\hline \multicolumn{2}{|c|}{ 6. Criteria of Success } & Now & Preferred \\
\hline $\mathrm{A}$ & $\begin{array}{l}\text { The organisation defines success on the basis } \\
\text { of the development of human resources, teamwork, } \\
\text { employee commitment and concern for people }\end{array}$ & & \\
\hline B & $\begin{array}{l}\text { The organisation defines success on the basis } \\
\text { of having the most unique or newest products. } \\
\text { It is a product leader and innovator. }\end{array}$ & & \\
\hline $\mathrm{C}$ & $\begin{array}{l}\text { The organisation defines success on the basis of } \\
\text { winning in the marketplace and outpacing the } \\
\text { competition. Competitive market leadership is key. }\end{array}$ & & \\
\hline $\mathrm{D}$ & $\begin{array}{l}\text { The organisation defines success on the basis } \\
\text { of efficiency. Dependable delivery, smooth } \\
\text { scheduling and low-cost production are critical. }\end{array}$ & & \\
\hline & Total & 100 & 100 \\
\hline
\end{tabular}

Fig. 4 The OCAI toolkit (adapted from reference [24]) 